\title{
Disrupting and Displacing Methodologies in STEM Education: from Engineering to Tinkering with Theory for Eco-Social Justice
}

\author{
Marc Higgins • Maria F. G. Wallace • \\ Jesse Bazzul \\ Published online: 14 September 2018 \\ (C) Ontario Institute for Educational Studies (OISE) 2018
}

\section{Why disrupting and displacing methodologies in STEM education matters}

It has been argued many times over the course of decades and across diverse paradigms that science, technology, engineering, and mathematics (STEM) education practices-as-usual (re)produce systems of dominance: be it patriarchy, heteronormativity, white supremacy, Eurocentrism, (neo-)colonialism, ableism, classism, labor inequity, anthropocentrism, and/or others. Thankfully, there are many who are doing the critical and creative work of (re)opening STEM education to the possibility of eco-social justice to-come through a plurality of productive approaches, orientations, and stances: anti-oppressive, anti-racist and critical race-based, decolonizing and de/colonizing, queer, Indigenous, gender-equitable, post-colonial, community-based and participatory, critical place-based, inter-species, and many more. Further, there are many examples taking richly critical and complicit stances to work within and against logics of exclusion. Yet, in doing so, many of these engagements are oft depoliticized and atheoretical practices of inclusion in ways that continue othering those formerly excluded, albeit differently. As readers of the field, we note the ways in which efforts often center around questions of curriculum and pedagogy; as they should, these are central and major nodes within STEM education. How coming-to-know-nature, coming-to-know-number, and coming-to-know-technology are conceptualized and enacted matters deeply: in terms of the curricular destinations and the pedagogical pathways that might allow such learning, as well as for whom. For example, as Megan Bang and Ananda Marin (2015) remind, the curricular inclusion of Indigenous perspectives is differentially problematic if we cannot also attend to the taken-for-granted and naturalized epistemological, ontological, and axiological commitments and enactments of what we are including perspectives into. As Bang and Marin (2015) state, if science education continues to "focus on 'settled'

\footnotetext{
M. Higgins $(\bowtie)$

University of Alberta, Edmonton, AB T6G 2R3, Canada

e-mail: marc1@ualberta.ca

M. F. G. Wallace

Millsaps College, Jackson, MS 39210, USA

e-mail: wallamg@millsaps.edu

J. Bazzul

University of Regina, Regina, Canada

e-mail: jesse.bazzul@uregina.ca
} 
phenomena as well as 'settled' perspectives and relations to phenomena" (p. 531), which rely on and reinforce recursive whiteness and settler privilege while simultaneously dismissing, diminishing, and denying Indigenous ways-of-living-with-nature, presence, and futurities, it will remain but a tokenistic inclusion which serves to distract from the more unsettling demands of this work and is often primarily an effort to reconceptualize and recenter the subject of dominance. Again, how curriculum, pedagogy, and its central nodes are conceptualized matters.

Similarly, methodology is also ${ }^{1}$ an important site in which the movements of power occur, differentially (re)producing articulations of dominance. While these often manifest in much more subtle ways, we argue that it remains important to ask ourselves how the diverse methodologies we employ in and through our research practices as scholars of STEM education contribute or work to maintain and privilege the prevailing trajectory of STEM education. To this end, highlighting the ways in which the disciplines discipline what counts as knowledge and, more to the point, knowledge production processes, Linda Tuhiwei Smith and colleagues (2016) ask, "are methodologies simply new technologies of cultural assimilation?" (p. 133). For Smith and colleagues (2016), attending to methodology is to address lingering colonial referents which lurk within our methodological constellation of concepts (e.g., voice, identity, data, and reflexivity). To engage in critical goals yet engage in "conventional" methodologies, whose taken-forgrantedness does not and cannot identify which conventions inform them, sends a subtle yet insidious message: that alternative perspectives need to be validated in and through the norms of dominance in order to "count." 2 There is a need to actively de-center these taken-for-granted notions and to pull through alternative and multiple ways of assembling theory, practice, and ethics. However, disrupting and displacing methodologies is not strictly a call for methodological pluralism, a means of "losing the way - as losing any sense that just one 'way' could ever be prefixed and privileged by the definite article" (Gough 2006, p. 640 , emphasis ours). It is also a call for "disrupting the hegemonic ways of seeing and how this relates to subjects making themselves dominant" (McKinley 2001, p. 76). We do not suggest that the critical and creative reworking of methodology is (wholly) a panacea to this poison. Nonetheless, there is purpose in critically engaging with the work of disrupting and displacing methodology: it is to at least dare to fail in new ways.

\section{From Research Design to De/Signing Research: From Engineering to Tinkering with Theory}

Still relevant today, Liz McKinley (2001) questions the ways in which dominance operated in STEM education through calling out how it responds to difference: as a form of "masking power with innocence." Primarily, McKinley (2001) sheds light on how a lack of knowledge (or a positional stance of "not knowing") often serves to (re)produce the norms of power; in turn, "we need to challenge the mask of innocence and ask ourselves how relations of domination and subordination regulate encounters in classrooms." (p. 76). While she speaks of and to pedagogy and curriculum, it offers a useful lens to discuss STEM research methodologies.

The theoretical landscape of educational research methodologies is shifting: the space of "innocence" resulting from a lack of knowledge is not what it was 20 years ago. ${ }^{3}$ Across diverse educational spaces, there are increasing calls to engage in and momentum around practices of disrupting and displacing

\footnotetext{
${ }^{1}$ Note that we signal also here. The articles herein offer perspectives that are both/and rather than either/or: we do not intend to suggest that methodology should be a focus instead of curriculum and pedagogy, but rather in addition to or as a multiplicative cross product.

${ }^{2}$ However, we recognize that the field(s) of STEM education are both politically and theoretically conservative. This poses a distinct challenge for introducing new forms of knowledge and knowledge production which take seriously othered thought-practices while remaining within the norms of intelligibility. Perhaps this is a call, after Cree scholar Cash Ahenakew (2016), for "writing in a way that makes what is invisible noticeably absent so that it can be remembered and missed." (p. 333), an invitation to signal our strategic complicities.

${ }^{3}$ Yet, actively pursued positional stances of "not knowing" or "not wanting to know" similarly persist, but exploring this is beyond the scope of an editorial. 
methodologies: the last decade being particularly momentous along these lines (e.g., special issues in journals such as Cultural Studies $\leftrightarrow$ Critical Methodologies, Educational Studies, International Journal of Qualitative Studies in Education). There are now multiple productive exemplars which critically engage methodological processes to disrupt and displace restrictive norms which linger and lurk with/in educational research and its concepts which left unchecked (re)articulate forms of oppressive power. The space of "innocence" which serves to mask methodological power is perhaps no longer tenable for not addressing taken-for-granted referents to system which (re)produce dominance, inequity, and foreclose the space of responsibility towards one another across lines of difference and power.

Because methodologies (even critical ones) often traffic in Majoritarian articulations, even when we work against them in critical STEM education, we argue that research can and should take a different approach from its very beginning: at the stage of research design. Elsewhere (Higgins et al. 2017), the notion of de/sign is offered to differ and defer that which design comes to signify: design as pre-existing, design as separate or separable from other aspects of research, and design as a means to achieve and justify the ends. Designing research in STEM education has intermittently been and must continue working towards being more than grabbing a "best fit" of the methodological rack or tailoring it to fit: resisting what Gayatri Spivak refers to as the "rage for unity" (Spivak 1976, p. xvi) which comes to mask the ways in which all methodologies consist of loosely assembled partial, situated, and relational meanings. De/sign is a "means of working within, against, and beyond the tailoring of research" (Higgins et al. 2017, p. 36). Further, de/sign is (a) accounting for and being accountable to that which conventional methodologies always already signify; (b) engaging in the creative and critical work of resignifying methodologies. This is why, in the call for papers, we asked the following: "What would it mean to engage in the work of de/signing research which critically disrupts and displaces methodologies in science, mathematics, engineering, and technology (STEM) education for ecosocial justice?"

In further considering the relationship between design and de/sign, we frame the exploration of the invited question with the dichotomous and relevant metaphors of engineering and tinkering: thinking specifically with Jacques Derrida's (1976) (mis)reading of Claude Lévi-Strauss' "La pensée sauvage" in which he both separates and blurs the distinctiveness between the two practices' metaphoricity. Research design can often prescriptively and prohibitively act as a signifier that sutures over the signified processes of designing and doing research. Similarly, engineering is the movement from the ends to the means, whereby the engineer makes appropriate selections from "the discourses of formal logic, and the pure sciences" (Spivak 1976, p. xix), picking concepts, categories, and constructs already purposed for their process (e.g., research as "best fit" and "best practices"). Consequently, "design" is often employed and understood as a method that exists a priori, instruments that support (rather than produce) research, that also includes and encompasses all of its conceptual apparatus: be it "objectivity," "cultural neutrality," "validity," or other. Because of the aforementioned ways that such constructs and categories often implicitly (re)produce systems of power, this special issue is a call to tinker with/in, rather than engineer, research and educational practices in STEM education.

In contrast to engineering, "the bricoleur [tinkerer] makes do with things that were meant perhaps for other ends" (Spivak 1976, p. xix). Tinkering reverses the ends/means hierarchy by privileging the means over the ends or the process over the product, even if this entails the very possibility of not achieving the specified goals. As Derrida (1976) argues, the ends (i.e., knowledge, truth) and the means of knowledge production (i.e., methodology) never come to coincide. The goal of (fully) achieving knowledge is not only empirically impossible, as Lévi-Strauss posited, but also theoretically so. Thus, for Derrida (1976), "the engineer should always be a sort of bricoleur [tinkerer]" (p. 139) while coming to recognize the very limitation of bricolage:

The only weakness of bricolage [tinkering] — but, seen as a weakness is it not irremediable? — is a total inability to justify itself in its own discourse. The already-there-ness of instruments and of concepts cannot be undone or re-invented (pp. 138-139). 
Just as the goals of engineering never come to be, Derrida cautions against treating the tinkerer's tools as if they themselves always were. Instead, he invites consideration of the tools themselves as the productive enactments of tinkerings past and to-come.

There is always a need for "simultaneously troubling and using the concepts [and conceptual lines] we think we cannot think without ..., keeping [them] as both limit and resource" (Lather 2007, p. 167-168). Lastly, because engineering/bricolage is always already a porous binary, this invites a critical consideration of bricolage vis-à-vis its ends, or what it produces: "all [tinkerings] are not equally worthwhile. Bricolage [tinkering] criticizes itself" (Derrida 1976, p. 139). However, because "methodological fabric is also a fabrication - a performative and non-separable enactment of the interconnected space between theory, practice, and ethics" (Higgins et al. 2017, p. 17) - methodological design is always already open to deconstruction, politics, and re (con)figuration.

This special issue collects the work of STEM education scholars doing the work of tinkering with theory, ${ }^{4}$ whether it be interrogating theories intended for STEM, or using theories unintended for that context to enact research in STEM education for social and ecological justice. The manuscripts herein are lived, engaged, and critically rich scholarship that tinkers within, against, and beyond these disciplinary spaces across the various stages of research and/as educational practice: design, delivery, analysis, and dissemination.

\section{Tinkering with Theory: An Overview of Collected Papers}

The papers herein are organized in two arcs. First, there are papers which tinker within and against STEM research methodologies by utilizing tools and techniques intended for within STEM, but refusing to use them in intended ways. Secondly, there are those working within and beyond STEM research methodologies by utilizing tools and techniques not intended for use within STEM education. These categories are not necessarily mutually exclusive, since materials, techniques, and concepts "intended" for STEM use is a matter of positionality, sociohistorical location, and context.

\section{Utilizing tools and techniques intended for STEM education, but refusing this intention}

Sara Giordano suggests that tinkering has become associated with and overcoded by masculinist desires within spaces of synthetic biology education. Thinking with decolonial scholar Maria Lugones and feminist science studies scholar Deboleena Roy to both use and trouble tinkering, Giordano engages in the play of resignification that tinkering invites: towards a more just (rather than just more) bio-hacking education practice. Nikki Rotas' contribution "puts to work" (Lather 2007) Baradian notions of diffraction in her work with children (ages 10-12) in an afterschool robotics club. Rotas' goal is to engender an understanding of design that can resist or escape rigid disciplinary pathways of both experience and design through cyborg embodiments of vision with wearable technologies. Can learning lead to and from alternate ontological and epistemologies that emerge from engagement with multiple assemblages and apparatuses? This is more or less, what Maria Wallace, Marc Higgins, and Jesse Bazzul emphasize in their attempt to dislodge the majoritarian concept of "nature" through a minor inquiry which traces the contours of Nature, honoring its inherent and ever-emerging local, differentiating, and queer potential. If education is to participate in finding new forms of collective existence, it will need to explore conceptions of nature that are more relational and contingent; conceptions bent on honoring and nurturing difference. Along similar yet different lines, Liz Defreitas and Nathalie Sinclair tinker within the all-too-subtle mathematical space of probability which comes to co-constitute cognitive psychology. Resignifying the relation between classical probability's "either/or" and learners whose inability to perceive and formalize mathematical abstraction, Defreitas

\footnotetext{
${ }^{4}$ It must be noted that the phrasing of Tinkering with Theory is a not-so-subtle nod to Jackson and Mazzei's (2012, 2017) Thinking with Theory. 
and Sinclair tinker with the "both/and" of quantum probability to invite consideration of superposition and indeterminacy in ways-of-knowing-Number (e.g., shape) as a potential differential gift.

\section{Utilizing tools and techniques not intended for STEM education}

The special issue also introduces tools, techniques, concepts and methodologies typically not employed in STEM education research. Michelle Wooten's cartographic introduces, among other things, an ontological landscape to the field of science education, such that new relationships and intensities can be realized (instead of rejected as they often are by mainstream science education). Wooten's work demonstrates, albeit subtly, a dissatisfaction with the lack of coherence that exists between science educators pursuing already established research regimes, and those that would venture to different spaces; and accordingly, cartography provides a tool for putting this work (all) in relation. Differently attending to representation, Shakhnoza Kayumova, Wenbo Zhang, and Kate Scantlebury's tinker with graphic comic image-text juxtapositions to bring about new relationships with data, continue along the lines of ontological exploration in terms of finding a plurality of ways to "connect" with, and embody relationships to, data and analysis. These authors set out to seriously question how unexamined methods of research can maintain hierarchies and hegemonic power relationships, and what this questioning might mean for doing equity work in science education. Last, but not least, Stacia Cedillo's critical essay introduces how a BlackCrit analytics of anti-blackness are useful approaches for showing how the US-Based corporate STEM movement, and Modern Western Science in general, is entangled with anti-black constructs, motives, and institutional arrangements. Importantly, Cedillo's working with BlackCrit reveals that even spaces that are deemed "open" which allow students to bring diverse ways-of-knowing-in-being, specifically open inquiry, are not immune to and from enactments of anti-Blackness; inviting a shift in the conversation from accessibility to directly addressing the central role that STEM plays in (re)producing individual and systemic racism.

A critical commentary by Annette and Noel Gough concludes the issue by doing three things. First, the commentary puts the special issue into relation with further relevant scholarship (e.g., critical science studies). Second, it gives readers assurance that the ethos for this special issue is not particularly new, and thus depicts a sustained "multi-generational" concern with theory and method/ology that continue to linger in educational research (including STEM fields). Third, it provides several areas for further exploration for interested educators and researchers.

Without further delay, we invite readers to take the time to sit with the topics, ideas, and tools that offer potential connections to research and practice, and to perhaps take a small step towards doing something differently. We can honestly say that exposure to the "disruptive diversity" in this special issue has provoked many little changes in us over the past year and half, and more than anything, we hope the spirit of the issue carries forward in multiple ways for the sake of the ecologies of relationships within which we live: their human, other-than-, and more-than-human beings with which we co-exist. Lastly, we echo the Goughs' commentary in stating that this work is neither new nor anywhere near done. For this work to refuse, resist, and resignify the field or STEM, as well as for it to be exemplary rather than extraneous, requires plurality and critical mass, as well as creative acts of perception and practice: again, STEM education needs methodological disruption and displacement for the possibly of justice to-come.

\section{References}

Ahenakew, C. (2016). Grafting Indigenous ways of knowing onto non-Indigenous ways of being. International Review of Qualitative Research, 9(3), 323-340.

Bang, M., \& Marin, A. (2015). Nature-culture constructs in science learning: Human/non-human agency and intentionality. Journal of Research in Science Teaching, 52(4), 530-544. 
Derrida, J. (1976). Of grammatology. Trans. G. C. Spivak. Baltimore, MD: John Hopkins University Press.

Gough, N. (2006). Shaking the tree, making a rhizome: Towards a nomadic geophilosophy of science education. Educational Philosophy and Theory, 38(5), 625-645.

Higgins, M., Madden, B., Bérard, M.-F., Lenz Kothe, E., \& Nordstrom, S. (2017). De/signing research in education: Patchwork (ing) methodologies with theory. Educational Studies, 43(1), 16-39.

Jackson, A. Y., \& Mazzei, L. A. (2012). Thinking with theory in qualitative research: Viewing data across multiple perspectives. New York, NY: Routledge.

Jackson, A. Y., \& Mazzei, L. A. (2017). Thinking with theory: A new analytic for qualitative inquiry. In N. K. Denzin \& Y. S. Lincoln (Eds.), The Sage Handbook of Qualitative Research (5th ed., pp. 717-727). Thousand Oaks, CA: Sage.

Lather, P. (2007). Getting lost: Feminist practices toward a double(d) science. Albany: SUNY.

McKinley, E. (2001). Cultural diversity: Masking power with innocence. Science Education, 85(1), 74-76.

Smith, L. T., Maxwell, T. K., Puke, H., \& Temara, P. (2016). Indigenous knowledge, methodology and mayhem: What is the role of methodology in producing Indigenous insights? A discussion from mātauranga Māori. Knowledge Cultures, 4(3), 131-156.

Spivak, G. C. (1976). Translator's preface. In J. Derrida, Of grammatology (G. C. Spivak, Trans.) (pp. ix-lxxxvii). Baltimore, MD: Johns Hopkins University Press. 